Research Article

\title{
Grey Relational Analysis Coupled with Principal Component Analysis for Optimization Design of the Machining Parameters in Electro-Discharge Diamond Face Grinding
}

\author{
G. K. Singh ${ }^{\mathrm{A}^{*}}$, N. K. Chauhan ${ }^{\dot{\mathrm{B}}}$, Rajeev Kumar ${ }^{\dot{\mathrm{C}}}$ and V. Yadava ${ }^{\dot{\mathrm{D}}}$ \\ ${ }^{\grave{A}}$ Mechanical Engineering Department, School of Engineering \& Technology, Galgotias University, Greater Noida (INDIA) \\ ${ }^{\dot{B}}$ Mechanical Engineering Department, JSS Academy of Technical Education, Noida (INDIA) \\ ${ }^{\mathrm{C}}$ Mechanical Engineering Department, IIMT College of Engineering, Greater Noida (INDIA) \\ ${ }^{\grave{D}}$ Mechanical Engineering Department, M.N.N.I.T., Allahabad(INDIA)
}

Accepted 10 January 2014, Available online 01 February 2014, Special Issue-2, (February 2014)

\begin{abstract}
Electro-Discharge Diamond Grinding (EDDG), a hybrid machining process comprising diamond grinding and electrodischarge grinding, has been developed for machining of electrically conductive difficult-to-machine very hard materials. The process employs simultaneous synergetic interactive effect of abrasion action and electro-discharge action. A self-designed face grinding setup is attached on ELEKTRA PULS EDM machine to use it as Electro-Discharge Diamond Face Grinding (EDDFG). This paper investigates optimization design of an EDDFG process performed on high speed steel (HSS).The major performance characteristics selected to evaluate the processes are material removal rate (MRR) and wheel wear rate (WWR), and the corresponding EDDFG parameters are wheel RPM, current, pulse ontime and duty factor. In this study, since the process is with multiple-performance characteristics, therefore, the grey relational analysis that uses grey relational grade as performance index is specially adopted to determine the optimal combination of EDDFG parameters. Moreover, the principal component analysis is applied to evaluate the weighting values corresponding to various performance characteristics so that their relative importance can be properly and objectively described. The results of confirmation experiments reveal that grey relational analysis coupled with principal component analysis can effectively be used to obtain the optimal combination of EDDFG parameters. Hence, this confirms that the proposed approach in this study can be a useful tool to improve the machining performance of EDDFG process.
\end{abstract}

Keywords: Hybrid machining, Diamond grinding, Electro-discharge grinding, Taguchi methodology, Response surface methodology, Grey relational analysis, Principal component analysis, Hybrid methodology.

\section{Introduction}

Recently manufacturing industries are facing challenges for machining of advanced difficult-to-machine materials (tough super alloys, ceramics, and composites) with stringent design requirements (high precision, complex shapes, and high surface quality) (Benedict, 1987). Conventional machining processes are not suitable for meeting these challenges effectively. If these processes are used then they require expensive equipment and large labour forces and hence making them economically unviable. To meet these challenges, new types of processes need to be developed, (Jain, 2002; Aoyama and Inasaki, 1986)

At present, many unconventional machining processes have gained acceptance and are widely prevalent in industries (Kozak and Kazimierz, 2001). Each of these unconventional machining processes has their own potential and limitations. One way of improving

*Corresponding author: G. K. Singh

DOI: http://dx.doi.org/10.14741/ijcet/spl.2.2014.05 technological performance of unconventional machining processes is to combine them with grinding process, which is termed as abrasive based hybrid machining processes. Hybrid machining processes (HMPs), which are combinations of two or more machining processes, are developed to exploit the potential advantages of constituent processes and diminish their disadvantages. In HMPs all constituent processes are directly involved in material removal. The performance of hybrid machining processes is considerably different than the performance of their constituent processes, when they are performed separately. Usually, the performance of a hybrid process is better than the sum of their individual performance with the same parameter setting (Aoyama and Inasaki, 1986; Kozak and Kazimierz, 2001; Choudhury et al., 1999). The abrasive based HMPs are developed by combining metal bonded abrasive grinding with EDM or ECM. Hybrid processes of ECM and grinding is called as electrochemical abrasive grinding (ECAG) whereas combination of EDM and grinding is called as electro-discharge abrasive grinding (EDAG).When metal boned diamond 
grinding wheel is used in EDAG then the process is termed as Electro-Discharge Diamond Grinding (EDDG).

EDDG can be operated in three different configurations (1) Electro-Discharge Diamond Surface Grinding (EDDSG) (2) Electro-Discharge Diamond Cut-off Grinding (EDDCG) (3) Electro-Discharge Diamond Face Grinding (EDDFG).

EDDFG is performed using flat face of the metal bonded diamond grinding wheel. In this mode, the metal bonded diamond grinding wheel rotates about vertical spindle axis and fed in a direction perpendicular to the machine table. While machining, the rotating wheel is fed downwards under the control of servo system. The metal bonded grinding wheel and the work surface are physically separated by a gap, the magnitude of which depends on the local breakdown strength of the dielectric for a particular gap voltage setting. The workpiece is thus simultaneously subject to heating due to electrical sparks occurring between the metal bonded grinding wheel and the workpiece, and abrasion by diamond grains with protrusion height more than the inter-electrode gap width. In this mode, the diameter of the metal bonded diamond Optimization methods grinding wheel is usually kept greater than that of the cylindrical workpiece diameter.

In EDDFG, the most important task is to select appropriate machining parameters for achieving high machining performance. Usually the machining parameters are determined based on pilot experimentation. The most important performance measuring parameters in EDDFG are MRR, WWR, ASR and grinding forces. The process parameters affecting the performance measures are wheel speed, current, pulse-on time and duty factor (Koshy et al., 1996). The mechanism of MRR and WWR during EDDFG is very complicated and process dependent. To select the machining parameters properly, several mathematical models (Phadke, 1989; Yuin and Alan, 2000; Singh et al., 2010; Singh et al., 2010; Singh et al.; Siddiquee et al., 2010; Lua et al., 2009) based on experimental and analytical approaches are required. Each of these approaches has its own limitations in giving a comprehensive and precise relationship between the machining variables and the machining behavior in a specific situation. In these approaches an objective function with constraints is required to be formulated and further optimal machining parameters can be obtained using optimization techniques. Therefore, considerable knowledge and experience are required to model and optimize the EDDFG process. In this paper, an alternative approach based on the grey relational analysis coupled with principal component analysis (Siddiquee et al., 2010; Lua et al., 2009) has been used to determine the optimum machining parameters more efficiently. Experiments were conducted under different machining parameters, namely, wheel RPM, current, pulse-on time and duty factor, and are optimized with considerations of MRR and WWR.

\section{Experimentation}

The Experimental studies were performed on an ELEKTRA PULS EDM machine attached with self designed grinding attachment in face grinding mode
(Figure 1). The setup consists of a metal bonded grinding wheel, motor, shaft, v-belt and bearing, mounted on the ram of the machine to rotate the metal bonded grinding wheel about an axis perpendicular to the machine table. While machining, the rotating wheel is fed downwards under servo control, for material removal in the face configuration. The metal bonded grinding wheel and the work surface are physically separated by a gap, the magnitude of which depends on the local breakdown strength of the dielectric for a particular gap voltage setting. The workpiece is thus simultaneously subject to heating due to electrical sparks occurring between the metal bonded grinding wheel and the workpiece, and abrasion by diamond grains with protrusion height larger than the inter-electrode gap. Specification of grinding wheel is shown in Table 1.

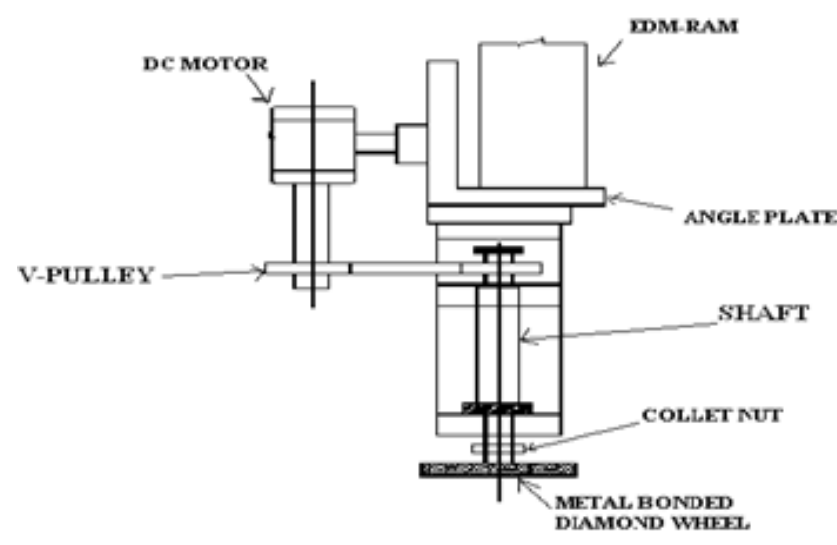

Fig.1 EDDFG setup

Table 1: Specification of grinding wheel

\begin{tabular}{|l|l|}
\hline Abrasive & Diamond \\
\hline Grain size & $80 / 100$ \\
\hline Grade & M (Medium) \\
\hline Concentration & $75 \%$ \\
\hline Bonding material & Bronze \\
\hline Depth of abrasive & $5 \mathrm{~mm}$ \\
\hline Wheel diameter & $30 \mathrm{~mm}$ \\
\hline
\end{tabular}

During experimentation the effect of various input parameters such as wheel speed, current, pulse on-time, and duty factor on the output parameters such as MRR and WWR have been studied. Experiments were performed on $25 \mathrm{~mm}$ diameter of cylindrical workpiece made of high speed steel (HSS). The spark erosion oil was used as dielectric liquid. Each workpiece was machined for 60 minutes before measuring output parameters. Each set of experiment was repeated three times. Amount of material removal after 60 minutes was obtained by finding weight difference before and after machining using precision electronic digital weight balance with $0.1 \mathrm{mg}$ resolution. The MRR is calculated by using the following formula:

$\operatorname{MRR}\left(\mathrm{mm}^{3} / \mathrm{min}\right)=\frac{\left(W_{i}-W_{f}\right) \times 1000}{t \times \rho}$

were $W_{i}$ is initial weight of workpiece in gram (before machining); $W_{f}$ is final weight of workpiece in gram (after 
machining); $t$ is machining time in minutes; $\rho$ is density of workpiece $\left(7.8 \mathrm{~g} / \mathrm{cm}^{3}\right)$.

The WWR is calculated by using the following formula:

$W R R(g / \mathrm{min})=\frac{W_{w i}-W_{w f}}{t}$

were $W_{w i}$ is initial weight of wheel in gram (before machining); $W_{w f}$ is final weight of wheel in gram (after machining); $t$ is machining time in minutes.

The numerical values of machining parameters at different levels are shown in Table 2. A pilot experimentation is done to decide the range of input parameters. In the present case, four parameters each at three levels with no interaction effect has been considered. The total degree of freedom (dof) has been calculated as Phadke, M.S. (1989):

dof $=(3-1) \times 4+1=9$

Hence, a standard $\mathrm{L}_{9}$ orthogonal array $(\mathrm{OA})$ is selected for experimental design matrix.

Table 2: Electro-discharge diamond face grinding parameters and their levels

\begin{tabular}{|c|c|c|c|c|}
\hline \multirow[b]{2}{*}{$\begin{array}{l}\text { EDDFG } \\
\text { parameters }\end{array}$} & \multirow[b]{2}{*}{ Symbol } & \multicolumn{3}{|c|}{ Levels } \\
\hline & & $\begin{array}{l}\text { Level } \\
1\end{array}$ & $\begin{array}{l}\text { Level } \\
2\end{array}$ & $\begin{array}{l}\text { Level } \\
3\end{array}$ \\
\hline Wheel RPM & $\mathrm{S}$ & 700 & 875 & 1050 \\
\hline Current (A) & $\mathrm{C}$ & 4 & 6 & 8 \\
\hline $\begin{array}{l}\text { Pulse } \quad \text { on-time } \\
(\mu \mathrm{s})\end{array}$ & $\mathrm{P}$ & 50 & 100 & 150 \\
\hline Duty factor & D & 0.57 & 0.63 & 0.7 \\
\hline
\end{tabular}

\section{Analysis and discussion}

Initially, the experimental results were used to obtain $\mathrm{S} / \mathrm{N}$ ratios for the performance characteristics to find a desirable result with the best performance and the smallest variance. MRR and WWR were the higher-the-better and lower-the-better performance characteristics. The experimental results listed in Table 3. The calculated S/N ratios of WWR and MRR (Phadke, 1989) are shown in Table 4. Usually, the larger the $\mathrm{S} / \mathrm{N}$ ratio is, the better is the performance characteristic. All the original sequences of $\mathrm{S} / \mathrm{N}$ ratio in Table 4 are normalized (Phadke, 1989) which are shown in Table 4. According to Singh et al. (2010), larger values of the normalized results correspond to better performance, and the maximum normalized results that are equal to 1 indicate the best performance. The results had shown in Table 4 the calculated grey relational coefficients (Singh et al., 2010) of MRR and WWR which are shown in Table 5. PCA was used to determine the corresponding weighting values for each performance characteristic to reflect its relative importance in the grey relational analysis. The elements of the array for multiple-performance characteristics listed in Table 5 represent the grey relational coefficient of each performance characteristic. These data were used to evaluate the correlation coefficient matrix and to determine the corresponding eigenvalues (Fung and Kang, 2005). The eigenvalues are shown in Table 6. The eigenvector corresponding to each eigenvalue is listed in
Table 7. The square of the eigenvalue matrix represents the contribution of the respective performance characteristic to the principal component. The contribution of MRR and WWR is shown in Table 7. These contributions are indicated as 0.4999 and 0.4999 . Moreover, the variance contribution for the first principal component characterizing the two performance characteristics is as high as $89.16 \%$. Hence, for this study, the squares of its corresponding eigenvectors were selected as the weighting values of the related performance characteristic, and coefficients w1, and w2 in (Siddiquee et al., 2010), were thereby set as 0.4999 and 0.4999 , respectively. The data listed in Table 5, the grey relational grades were calculated as shown in Table 5 . Thus, the optimisation design was performed with respect to a single grey relational grade rather than complicated performance characteristics.

Table 3: Experimental results using $\mathrm{L}_{9} \mathrm{OA}$

\begin{tabular}{|l|l|l|l|l|l|l|}
\hline \multirow{2}{*}{ Exp. No. } & \multicolumn{4}{|l|}{ Factor levels } & \multicolumn{2}{c|}{$\begin{array}{l}\text { Responses of quality } \\
\text { characteristics }\end{array}$} \\
\cline { 2 - 7 } & S & C & P & D & MRR & WWR \\
\hline 1 & 1 & 1 & 1 & 1 & 0.4114 & 0.0006 \\
\hline 2 & 1 & 2 & 2 & 2 & 0.9351 & 0.00361 \\
\hline 3 & 1 & 3 & 3 & 3 & 1.3069 & 0.01006 \\
\hline 4 & 2 & 1 & 2 & 3 & 0.7294 & 0.00164 \\
\hline 5 & 2 & 2 & 3 & 1 & 1.7075 & 0.00867 \\
\hline 6 & 2 & 3 & 1 & 2 & 1.3656 & 0.00433 \\
\hline 7 & 3 & 1 & 3 & 2 & 0.8129 & 0.00222 \\
\hline 8 & 3 & 2 & 1 & 3 & 1.2684 & 0.00375 \\
\hline 9 & 3 & 3 & 2 & 1 & 1.2786 & 0.00338 \\
\hline
\end{tabular}

Table 4: $\mathrm{S} / \mathrm{N}$ ratios for $\mathrm{MRR}$ and $\mathrm{WWR}$ for single objective optimization

\begin{tabular}{|l|l|l|l|l|}
\hline \multirow{2}{*}{ Exp.No. } & \multicolumn{2}{|l|}{ S/N ratio (dB) } & \multicolumn{2}{l|}{ Normalization } \\
\cline { 2 - 5 } & MRR & WWR & MRR & WWR \\
\hline $\begin{array}{l}\text { Ideal } \\
\text { sequence }\end{array}$ & & & 1.0000 & 1.0000 \\
\hline 1 & -7.7231 & 64.4370 & 0.2409 & 1.0000 \\
\hline 2 & -0.5828 & 48.8499 & 0.5476 & 0.1662 \\
\hline 3 & 2.3248 & 39.9480 & 0.7653 & 0.0596 \\
\hline 4 & -2.7406 & 55.7031 & 0.4271 & 0.3658 \\
\hline 5 & 4.6472 & 41.2396 & 1.0000 & 0.0692 \\
\hline 6 & 2.7064 & 47.2702 & 0.7997 & 0.1385 \\
\hline 7 & -1.7992 & 53.0729 & 0.4760 & 0.2702 \\
\hline 8 & 2.0651 & 48.5194 & 0.7428 & 0.1600 \\
\hline 9 & 2.1346 & 49.4217 & 0.7488 & 0.1775 \\
\hline
\end{tabular}

The response table of Taguchi method was employed to calculate the average grey relational grade for each EDDFG parameter level. It was done by sorting the grey relational grades corresponding to levels of the EDDFG parameter in each column of the orthogonal array and taking an average on those with the same level. Basically, the larger the grey relational grade, the better are the multiple-performance characteristics. Accordingly, we selected the level that gave the largest average response. From the response table for the grey relational grades shown in Table 8, the best combination of the EDDFG parameters is the set with $\mathrm{S}_{1}$ (wheel RPM of 875), $\mathrm{C}_{2}$ 
(current of $6 \mathrm{~A}$ ), $\mathrm{P}_{1}$ (pulse on-time of $50 \mu \mathrm{s}$ ) and $\mathrm{D}_{1}$ (duty factor of 0.57).

Table 5: The calculated grey relational coefficient

\begin{tabular}{|l|l|l|l|l|}
\hline Exp.No. & MRR & WWR & $\begin{array}{l}\text { Grey } \\
\text { relational } \\
\text { grade }\end{array}$ & Order \\
\hline 1 & 0.3333 & 1.0000 & 0.6666 & 2 \\
\hline 2 & 0.5416 & 0.4399 & 0.4907 & 9 \\
\hline 3 & 0.7268 & 0.3333 & 0.5300 & 6 \\
\hline 4 & 0.4555 & 0.5836 & 0.5195 & 7 \\
\hline 5 & 1.0000 & 0.3454 & 0.6726 & 1 \\
\hline 6 & 0.7610 & 0.4162 & 0.5885 & 3 \\
\hline 7 & 0.4894 & 0.5186 & 0.5039 & 8 \\
\hline 8 & 0.7053 & 0.4347 & 0.5699 & 5 \\
\hline 9 & 0.7109 & 0.4491 & 0.5799 & 4 \\
\hline
\end{tabular}

Table 6: The eigenvalues and explained variation for principal components

\begin{tabular}{|l|l|l|}
\hline Principal component & Eigenvalue & $\begin{array}{l}\text { Explained } \\
\text { variation (\%) }\end{array}$ \\
\hline First & 0.2167 & 10.83 \\
\hline Second & 1.7833 & 89.16 \\
\hline
\end{tabular}

Table 7: The eigenvectors for principal components and the contribution of each individual quality characteristic

\begin{tabular}{|c|c|c|c|}
\hline \multirow[b]{2}{*}{$\begin{array}{l}\text { Quality } \\
\text { Characteristic }\end{array}$} & \multicolumn{2}{|l|}{ Eigenvector } & \multirow[b]{2}{*}{ Contri-bution } \\
\hline & $\begin{array}{l}\text { First Principal } \\
\text { component }\end{array}$ & $\begin{array}{l}\text { Second } \\
\text { Principal } \\
\text { Component }\end{array}$ & \\
\hline MRR & 7071 & 7071 & 0.4999 \\
\hline WWR & 7071 & 7071 & 0.4999 \\
\hline
\end{tabular}

The results of ANOVA for the grey relational grade are listed in Table 9. It shows that duty factor is the most significant EDDFG process parameters for affecting the multiple performance characteristics due to its highest percentage contribution amongst the process parameters. Table 9 further shows that the EDDFG process parameter, wheel RPM and Current, does not have statistically significant effect on the multiple performance characteristics. It may be noted that wheel RPM and Current might have an effect on some response variables individually but its effect might be insignificant, when all response variables are considered together with different weightages as it has been observed in the present experimental investigation. After obtaining the optimal level of the EDDFG parameters, the next step is to verify the improvement of the performance characteristics using this optimal combination. Table 10 compares the results of the confirmation experiments using the optimal EDDFG parameters $\left(\mathrm{S}_{2}, \mathrm{C}_{2}, \mathrm{P}_{1}, \mathrm{D}_{1}\right)$ obtained by the proposed method and with those of the initial EDDFG parameters $\left(\mathrm{S}_{1}, \mathrm{C}_{1}, \mathrm{P}_{1}, \mathrm{D}_{1}\right)$.
Table 8: Response table for the grey relational grade

\begin{tabular}{|l|l|l|l|l|l|}
\hline Symbol & $\begin{array}{l}\text { Machining } \\
\text { Parameter }\end{array}$ & Level 1 & Level 2 & $\begin{array}{l}\text { Level } \\
3\end{array}$ & $\begin{array}{l}\text { Max- } \\
\text { Min }\end{array}$ \\
\hline S & Wheel RPM & 0.5624 & 0.5935 & 0.5512 & 0.0423 \\
\hline C & Current & 0.5633 & 0.5777 & 0.5661 & 0.0144 \\
\hline P & $\begin{array}{l}\text { Pulse on } \\
\text { Time }\end{array}$ & 0.6083 & 0.5300 & 0.5668 & 0.0783 \\
\hline D & Duty Factor & 0.6397 & 0.5277 & 0.5398 & 0.1120 \\
\hline
\end{tabular}

Table 9: Result of analysis of variance for multiple quality characteristics (MRR and WWR)

\begin{tabular}{|c|c|c|c|c|c|c|}
\hline 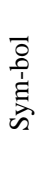 & 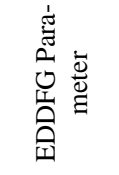 & 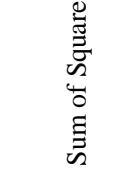 & o & 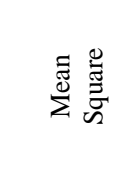 & 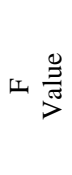 & 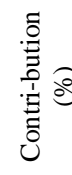 \\
\hline $\mathrm{S}$ & $\begin{array}{l}\text { Wheel } \\
\text { RPM }\end{array}$ & 0.002886 & 2 & 0.001441 & - & 8.22 \\
\hline $\mathrm{C}$ & Current & 0.000349 & 2 & 0.0001749 & - & 0.994 \\
\hline $\mathrm{P}$ & $\begin{array}{l}\text { Pulse on } \\
\text { Time }\end{array}$ & 0.009196 & 2 & 0.0045983 & $\begin{array}{l}5.68 \\
5 \\
\end{array}$ & 26.2 \\
\hline D & $\begin{array}{l}\text { Duty } \\
\text { Factor }\end{array}$ & 0.02267 & 2 & 0.0113352 & $\begin{array}{l}14.0 \\
15\end{array}$ & 64.59 \\
\hline \multicolumn{2}{|c|}{$\begin{array}{l}\text { Pooled } \\
\text { Error }\end{array}$} & 0.003235 & 4 & 0.0008087 & & \\
\hline \multicolumn{2}{|c|}{ Total } & 0.035098 & 8 & & & 100 \\
\hline
\end{tabular}

Table 10: Comparison between initial level and optimal level

\begin{tabular}{|l|l|l|l|}
\hline & $\begin{array}{l}\text { Best } \\
\text { Combination }\end{array}$ & $\begin{array}{l}\text { MRR } \\
\left(\mathrm{mm}^{3} / \mathrm{min}\right)\end{array}$ & WWR (g/min) \\
\hline $\begin{array}{l}\text { Initial } \\
\text { design }\end{array}$ & $\mathrm{S}_{1} \mathrm{C}_{1} \mathrm{P}_{1} \mathrm{D}_{1}$ & 0.4114 & 0.00060 \\
\hline $\begin{array}{l}\text { Optimal } \\
\text { Design }\end{array}$ & $\mathrm{S}_{2} \mathrm{C}_{2} \mathrm{P}_{1} \mathrm{D}_{1}$ & 1.6254 & 0.00426 \\
\hline Final Gain & & 1.214 & $\begin{array}{l}0.00366 \\
\text { (Deteriorating) }\end{array}$ \\
\hline
\end{tabular}

\section{Conclusions}

This paper presents an application of grey relational analysis coupled with principal component analysis for optimizing the EDDFG process parameters for HSS. The principal component analysis, used to determine the corresponding weighting values of each performance characteristics whilst applying grey relational analysis to a problem with multiple-performance characteristics, is proven to be capable of objectively reflecting the relative importance for each performance characteristic. Based on analysis of variance, the major controllable factor significantly affecting the multiple-performance characteristics is duty factor with a desired total contribution of $64.59 \%$. The optimal combination of the EDDFG parameters obtained from the proposed method is the set with $\mathrm{S}_{2}, \mathrm{C}_{2}, \mathrm{P}_{1}$ and $\mathrm{D}_{1}$. The corresponding confirmation tests show that MRR is improved from 1.214 $\mathrm{mm}^{3} / \mathrm{min}$, but WWR will be deteriorating from 0.00366 $\mathrm{g} / \mathrm{min}$.

26 | International Conference on Advances in Mechanical Sciences 2014 


\section{References}

T. Aoyama, and I. Inasaki, (1986), Hybrid machiningcombination of electrical discharge machining and grinding, Proc. of the $14^{\text {th }}$ North American manufacturing research Conf., SME, pp. 654-661.

G. F. Benedict, (1987), Nontraditional Manufacturing Processes, New York: Marcel Dekker.

S.K. Choudhury, V.K. Jain and M. Gupta, (1999), Electrical discharge diamond grinding of high speed steel, Machining Science and Technology, Vol.3, No.1, pp.91-95.

H.C. Fung and P.C. Kang (2005), Multi-response optimization in friction properties of PBT composites using Taguchi method and principal component analysis, Journal of Materials Processing Technology, Vol.170 pp.602-610.

H. Hotelling, (1993), Analysis of a complex of statistical variables into principal components, Journal of Educational Psychology, Vol. 24, pp. 417-441.

V.K. Jain, (2002) Advanced Machining Processes, New Delhi: Allied, Ch.1.

J. Kozak and E.O. Kazimierz (2001), Selected problems of abrasive hybrid machining, Journal of Materials Processing Technology, Vol. 109, pp.360-366.

P. Koshy, V.K. Jain, and G.K. Lal (1996), Mechanism of material removal in electrical discharge diamond grinding, International Journal of Machine Tools \& Manufacture, Vol. 36, pp.1173-1175.

H.S.Lua, C.K Chang, N.C. Hwang, and C.T. Chung, (2009), Grey relational analysis coupled with principal component analysis for optimization design of the cutting parameters in high-speed end milling, Journal of Materials Processing Technology, Vol. 209, pp. 3808-3817.
J.A. McGeough (1988), Advanced Method of Machining, London: Chapman and Hall.

M.S. Phadke (1989), Quality Engineering Using Robust Design, Prentice-Hall: Englewood Cliffs, NJ.

K. Pearson, (1901), On lines and planes of closest fit to systems of points in space, Philosophical Magazine Series, Vol. 62 pp.559-572.

G. K Singh, V. Yadava and R. Kumar (2010), Multi response Optimization of Electro-Discharge Diamond Face Grinding Process Using Robust Design of Experiments, Materials and Manufacturing Processes, Vol. 25, pp. 1-6.

G. K. Singh, V. Yadava, and R. Kumar (2010), Diamond face grinding of WC-Co composite with spark assistance: Experimental study and parameter optimization. International Journal of Precision Engineering and Manufacturing, Vol. 11(4), pp. 509-518. G. K. Singh, V. Yadava, and R. Kumar (2010), Experimental study and parameter optimization of electro-discharge diamond face grinding, International Journal of Abrasive Technology in press.

A. N. Siddiquee, Z. A. Khan, and Z. Mallick, (2010), Grey relational analysis coupled with principal component analysis for optimisation design of the process parameters in in-feed centreless cylindrical grinding, The International Journal of Advanced Manufacturing Technology, Vol.46, pp.983-992.

W.U. Yuin and W.U. Alan, (2000), Taguchi Methods for Robust Design, ASME Press: New York. 